\title{
Newborn screening by whole genome sequencing? Not quite yet.
}

\author{
Stephen Scherer, Ph.D. ${ }^{1}$, Ronald Cohn, MD, FACMG ${ }^{2}$, Christian Marshall, \\ Ph.D. ${ }^{3}$ \& Michael Szego, Ph.D. ${ }^{4}$
}

1. The Centre for Applied Genomics and Program in Genetics and Genomic Biology, The Hospital for Sick Children, Toronto, ON. McLaughlin Centre and Department of Molecular Genetics, University of Toronto, Toronto, ON. 2. Program in Genetics and Genome Biology, Division of Clinical and Metabolic Genetics, The Hospital for Sick Children, Toronto, ON. 3. Department of Paediatric Laboratory Medicine, The Hospital for Sick Children, Toronto, ON. 4. The Centre for Clinical Ethics, St. Joseph's Health Centre, Toronto, ON.

Advances in sequencing technology and informatics have made it possible to elucidate the genomes of individuals ${ }^{1,2}$. With falling sequencing costs, and improving accuracy and speed of the technology, application of whole genome sequencing (WGS) is increasing in clinical research, and will likely soon be a clinical test. Here we propose that, while WGS holds great promise, it is premature to employ it as a newborn screening tool. We will suggest a tiered screening model that could be employed in the future.

Newborn screening programs provide accurate tests with high clinical utility to identify treatable conditions before symptoms are evident ${ }^{3}$. WGS is a relatively new test whose clinical validity and utility are still being established. The Centre for Genetic Medicine at the Hospital for Sick Children in Toronto (SickKids) has launched the "genome clinic", a five-year cohort study to compare the efficacy of WGS to conventional genetic testing ${ }^{4}$. This study is being performed because WGS shows great promise as a diagnostic tool that will better guide treatment. First, individuals metabolize drugs at different rates, and WGS can help clinicians to prescribe the most effective medication and dose for each patient ${ }^{5}$. Second, the use of WGS can expedite diagnosis compared to conventional -- often sequential -- genetic testing, particularly in cases of unclear clinical diagnoses or atypical disease manifestations ${ }^{6}$. Third, WGS can lead to individualized treatment. For example, a boy with life-threatening inflammatory bowel disease had not responded to standard therapies, but whole exome sequencing identified a mutation in a gene associated with a blood disorder; as a consequence clinicians performed a hematopoetic stem cell transplant and the boy's symptoms improved ${ }^{7}$.
WGS is a promising technology, but there are some barriers before its clinical utility can be established. First, the methodology is highly, but not perfectly accurate, for a variety of technical reasons ${ }^{8}$. Given the large data set, even a small false positive rate translates into many errors $^{3}$. Second, the interpretation of genomic variants is challenging, and can be a source of error and uncertainty. In silico prediction tools are imperfect for detecting pathogenic variants, and even the most up-to-date lists of pathogenic variants from large-scale databases are incomplete and sometimes inaccurate ${ }^{3,9}$. Third, genome analysis is still time-consuming, usually including manual curation ${ }^{10}$. As technology and analysis tool improve, these issues will likely be addressed.

Current newborn screening programs are efficient at informing a child's parents of positive screen results for the selected tests, typically chosen due to immediate health implications for the child. In contrast, WGS is a sweeping collection of all genomic data, both massive and complex to interpret, and has the potential to reveal unwanted or harmful information. There is controversy about what results should be returned to patients/parents from such analyses ${ }^{11,12}$. Should most data be masked, and only the genes revealed that have immediate relevance to the newborn? Or should we take the opportunity for more information? For example, should pathogenic mutations in BRCA1 be assayed for in newborn screening given the health implications for the biological parents and the future health implications for the child? With prior consent, the SickKids genome clinic will inform parents about variants associated with treatable adult onset disorders found in their child if the child is unable to consent for herself. Such findings may have health implications for the parents, with 
considerations in the best interests of their children ${ }^{13}$. Our position is consistent with American College of Medical Genetics (ACMG) guidelines ${ }^{14}$ which suggest that medically actionable conditions (most of which are adult-onset) should be tested for at any age, provided there is consent. This position on testing for adult-onset conditions in young children (or any child not capable of consenting to the test) is controversia| ${ }^{15,16}$.

Given the technical efficiency of a single full genomic scan, we foresee that eventually every individual will have such data as part of his medical record, and probably it will take place at birth (if not before). In the short term, however, WGS is not appropriate as a newborn screening tool, but plans are needed in anticipation of its eventuality. For now, WGS is best employed for targeted diagnostic investigations, and we propose a tiered approach to future applications in screening. With fully automated interpretation, WGS could be performed for all newborns, with a series of different informatics filters to be applied to the data as the child ages. In addition, whenever a patient interacts with a healthcare provider and genetic testing is recommended, the WGS data could be probed selectively for diagnosis and/ or treatment. We anticipate that WGS, used as a screening tool in a tiered manner, could positively contribute to the health of Canadians from birth until adulthood. Not yet but coming.

\section{Acknowledgements}

The authors thank Dr. Janet Buchanan for helpful commentary.

\section{References}

1. Levy S, Sutton G, Ng PC, Feuk L, Halpern AL, Walenz BP, et al. The diploid genome sequence of an individual human. PLoS biology. 2007;5(10):e254. Epub 2007/09/07.

2. Wheeler DA, Srinivasan M, Egholm M, Shen Y, Chen L, McGuire A, et al. The complete genome of an individual by massively parallel DNA sequencing. Nature. 2008;452(7189):872-6. Epub 2008/04/19.

3. Canadian Agency for Drugs and Technologies in Health. Newborn Screening for Disorders and Abnormalities in Canada. 2015 [cited 2015 March 9]; Available from: http://www.cadth.ca/products/environmental-scanning/ environmental-scans/newborn-screening.

4. Bowdin S, Ray PN, Cohn RD, Meyn MS. The genome clinic: a multidisciplinary approach to assessing the opportunities and challenges of integrating genomic analysis into clinical care. Human mutation. 2014;35(5):513-9. Epub 2014/03/07.

5. Harper AR, Topol EJ. Pharmacogenomics in clinical practice and drug development. Nature biotechnology. 2012;30(11):1117-24. Epub 2012/11/10.

6. Johansen Taber KA, Dickinson BD, Wilson M. The promise and challenges of next-generation genome sequencing for clinical care. JAMA internal medicine. 2014;174(2):275-80. Epub 2013/11/13.

7. Worthey EA, Mayer AN, Syverson GD, Helbling D, Bonacci BB, Decker B, et al. Making a definitive diagnosis: successful clinical application of whole exome sequencing in a child with intractable inflammatory bowel disease. Genetics in medicine : official journal of the American College of Medical Genetics. 2011;13(3):255-62. Epub 2010/12/22.

8. Pang AW, Macdonald JR, Yuen RK, Hayes VM, Scherer SW. Performance of high-throughput sequencing for the discovery of genetic variation across the complete size spectrum. G3. 2014;4(1):63-5. Epub 2013/11/07.

9. Xue $\mathrm{Y}$, Chen $\mathrm{Y}$, Ayub Q, Huang N, Ball EV, Mort M, et al. Deleterious- and disease-allele prevalence in healthy individuals: insights from current predictions, mutation databases, and population-scale resequencing. American journal of human genetics. 2012;91(6):1022-32. Epub 2012/12/12.

10. Bell CJ, Dinwiddie DL, Miller NA, Hateley SL, Ganusova EE, Mudge J, et al. Carrier testing for severe childhood recessive diseases by next-generation sequencing. Science translational medicine. 2011;3(65):65ra4. Epub 2011/01/14.

11. Anderson JA, Hayeems RZ, Shuman C, Szego MJ, Monfared N, Bowdin S, et al. Predictive genetic testing for adult-onset disorders in minors: a critical analysis of the arguments for and against the 2013 ACMG guidelines. Clinical genetics. 2014. Epub 2014/07/22.

12. Clayton EW, McCullough LB, Biesecker LG, Joffe S, Ross LF, Wolf SM, et al. Addressing the ethical challenges in genetic testing and sequencing of children. The American journal of bioethics : AJOB. 2014;14(3):3-9. Epub 2014/03/07.

13. Szego MJ, Meyn MS, Anderson JA, Hayeems R, Shuman C, Monfared N, et al. Predictive genomic testing of children for adult onset disorders: a Canadian perspective. The American journal of bioethics : AJOB. 2014;14(3):19-21. Epub 2014/03/07.

14. Green RC, Berg JS, Grody WW, Kalia SS, Korf BR, Martin CL, et al. ACMG recommendations for reporting of incidental findings in clinical exome and genome sequencing. Genetics in medicine : official journal of the American College of Medical Genetics. 2013;15(7):565-74. Epub 2013/06/22.

15. Knoppers BM, Senecal K, Borry P, Avard D. Whole-genome sequencing in newborn screening programs. Science translational medicine. 2014;6(229):229cm2. Epub 2014/03/29. 
16. Zawati MH, Parry D, Thorogood A, Nguyen MT, Boycott KM, Rosenblatt D, et al. Reporting results from whole-genome and whole-exome sequencing in clinical practice: a proposal for Canada? Journal of medical genetics. 2014;51(1):68-70. Epub 2013/10/01.

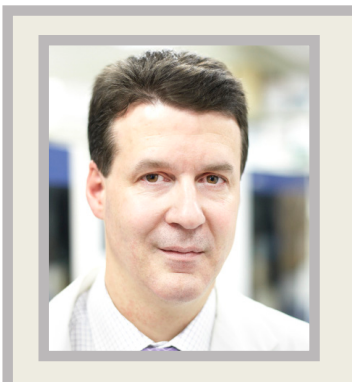

\section{Stephen Scherer}

Dr. Stephen W. Scherer is the Director of The Centre for Applied Genomics, The Hospital for Sick Children and Director, McLaughlin Centre, University of Toronto. He is also a professor in the Department of Molecular Genetics at the University of Toronto.

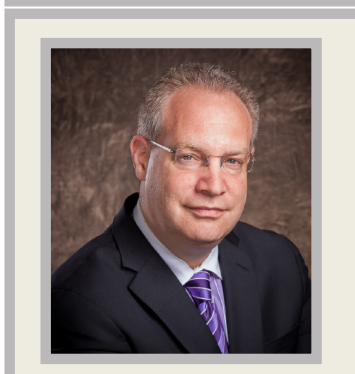

\section{Ronald Cohn}

Dr. Ronald Cohn joined The Hospital for Sick Children as the Chief of the Division of Clinical and Metabolic Genetics, Co-Director of the Centre for Genetic Medicine and Senior Scientist in September 2012. He also became the Inaugural Women's Auxiliary Chair in Clinical and Metabolic Genetics in April of 2013, as well as joining the department of Molecular Genetics at the University of Toronto.

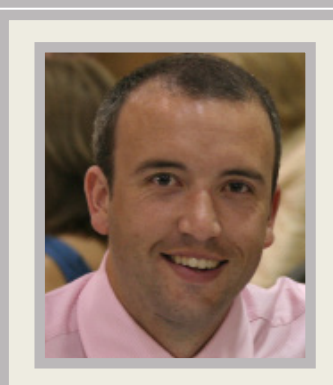

\section{Christian Marshall}

Dr. Christian Marshall is currently an Associate Director in the Department of Pediatric Laboratory Medicine at The Hospital for Sick Children and is working on the implementation of genome sequencing technologies in the diagnostic laboratory. $\mathrm{He}$ is also an assistant professor in the Department of Laboratory Medicine and Pathobiology, University of Toronto, Toronto, ON.

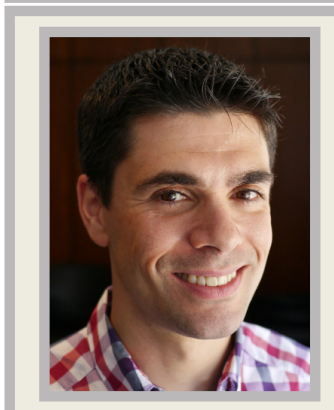

\section{Michael Szego, PhD, MHSc}

Dr. Michael Szego is a clinical ethicist at the Centre for Clinical Ethics (a joint venture between Providence Healthcare, St. Joseph's Health Centre, and St. Michael's Hospital). He is a research ethics consultant at the Centre for Applied Genomics at The Hospital for Sick Children and an assistant professor in the Department of Family and Community Medicine at the University of Toronto. 